\title{
Outsiders Within: College Sport as an Avenue to Integrate East Asian International Students
}

\begin{abstract}
Xiaochen Zhou', Anthony Pizzo², and Daniel C. Funk ${ }^{3}$
'East Stroudsburg University, ${ }^{2}$ La Salle University, ${ }^{3}$ Temple University

International students represent a valuable stakeholder for U.S. institutions of higher learning, but universities often struggle to integrate this unique student group into the university community. Drawing upon social identity theory and the acculturation process, this study explored how college sport contributes to international students' university identification using narrative interviews with East Asian international students who attended college football events at a U.S. university. Findings revealed international students mainly interacted with their co-national peers during college football games while associating with the football spectator subgroup through the influence of American students, which contributed to their university identity. Theoretically, our research shows how college sport and acculturation interact to influence the various social identities of international students. Practically, our research offers guidance on how universities can use college sport to initiate organic social interactions between students from different cultures and empower international students to identify as essential members of universities.
\end{abstract}

Keywords: Social identity, Acculturation, College sport, International students, Narrative interviews

International students are important stakeholders for U.S. institutions of higher education. During the 2019-20 academic year, over one million international students were enrolled at U.S. universities and contributed $\$ 38.7$ billion to the U.S. economy (NAFSA, 2020). Despite a recent drop in new international enrollment, experts expect the total number of international students in the U.S. to remain stable and U.S. universities will continue to remain popular destinations for studying abroad (Moody, 2020). In addition to their economic impact, international students also create cultural and intellectual capital by enhancing diversity, fostering cultural exchange, and enriching the U.S. workforce (Lapchick, 2010; Smith \& Khawaja, 2011). For instance, nearly $25 \%$ of leading startup companies had a founder who came to the U.S. for educational purposes (National Foundation for American Policy, 2018). The benefits international students bring to the U.S. has led universities to embrace these students for mutual success. 
Despite their significant contributions, international students often find it challenging to integrate to U.S. universities. While international students study abroad to pursue educational advancement, most are also motivated by an interest in participating in larger socio-cultural exchanges, such as exploring different cultures and making new friends (Holtbrügge \& Engelhard, 2016). However, even as international students strive to adjust to the culture and lifestyle of their universities and U.S. society, they are likely to feel isolated from mainstream U.S. culture (Zhou et al., 2018). Problems with a foreign language (e.g., American English), lack of understanding of American culture, and immigration-related issues are just a few examples of the many challenges that students' experience when studying in the U.S. (Smith \& Khawaja, 2011; Wu et al., 2015). These challenges are particularly troublesome for East Asian students, the largest international student group studying in the U.S., considering the large cultural gap between East Asia and the U.S. (Li et al., 2019). Compared to students from other parts of the world such as Europe and South Asia, East Asian international students often experience communication difficulties and perceived prejudice, making them less likely to seek help for their respective challenges (Frey \& Roysircar, 2006; Jones \& Kim, 2013). Because of this situation, U.S. universities are seeking strategies to better integrate international students, particularly those from East Asia, onto their campuses.

One way to mitigate challenges confronting international students and U.S. universities is to utilize college sport to foster students' university identity. University identity forms when students associate their university membership with emotional and cognitive meanings (Clopton, 2011). Students who identify with their universities are more likely to maintain psychological wellbeing, build a strong social network, achieve academic success, and donate back to the university (Brunette et al., 2017; Wann et al., 2008). Among international students, university identity positively influences their social relationships within the university community (Quinton, 2020), university satisfaction, and general life wellbeing (Cho \& Yu, 2015). As such, a strong university identity among international students is a highly sought-after outcome for university administrators (Steiner et al., 2013).

While recreational sport (Allen et al., 2010) and student clubs (Wu et al., 2015) can also facilitate the integration of international students, college sport offers intriguing integration potency considering its significant role at U.S. universities. Sport spectatorship in general can facilitate individuals' social psychological wellbeing (Inoue et al., 2015), and college sport in particular is regarded as universities' "front porch" - as university athletic programs are often the first thing that comes to mind when thinking about a university (Pratt, 2013). College sport, especially college football, plays an important role in both the culture of U.S. higher education and broader American culture (Toma, 2003). However, research has shown that international students tend to have limited knowledge and experience with college sport (Kang et al., 2014). Despite this unfamiliarity, the distinct cultural aspect of college sport presents an opportunity for institutions of higher education to improve integration of international students. 
To explore the potential of college sport to integrate international students to the university community, the current research investigated how attending college football games influenced international students' university identity with a focus on East Asian international students. We explored international students' multiple social identities (i.e., relational group, subgroup, and superordinate group identities) that form around the university and college football using social identity theory (Tajfel \& Turner, 1979; Lock \& Funk, 2016). In addition, we applied the notion of acculturation, the process of adjusting to a different culture (Berry, 1997; Ward, 2001), to examine how international students perceive and react to college football spectacles as a cultural subject.

\section{Theoretical Background}

\section{College Sport and International Students}

Within the field of sport and higher education studies, a significant body of literature has examined the social impact of college sport on university students. Existing studies have examined how college sport influences students' social capital (Clopton, 2011), psychological health (Wann et al., 2008), and university identification (Katz \& Heere, 2016; Kim et al., 2016). While some studies report that college sport promotes positive social changes (e.g., Katz \& Heere, 2016), others report the opposite (e.g., Clopton, 2011). Clopton (2011) specifically argued that identifying with college sport may bond students into small homogeneous social networks prohibiting the development of a larger cohesive university community. Collectively, the social integration function of college sport among international students remains ambiguous.

There are two streams of literature related to college sport and international students. The first research stream focuses on international student-athletes. Overall, this line of research seeks to understand how international student-athletes differ from their domestic peers (e.g., Popp et al., 2009) and their adjustment and integration issues (e.g., Lee \& Opio, 2011). Despite its relative importance, this line of research provides limited insights to the experience of international non-athlete students, who receive far less institutional support than their student-athlete peers (Forbes-Mewett \& Pape, 2019).

The second stream of research examines international students' participation in sport and leisure, with limited research focusing on spectatorship. Overall, this body of literature suggests positive dynamics between sport participation and students' social adjustment to college life and the U.S. society (Allen et al., 2010; Glass et al., 2014). Among studies examining the spectator perspective, a common finding was international students' lows rates of game attendance despite considerable interest in college sport (Kwon \& Trail, 2011; Kang et al., 2014). While insightful, these studies omit how college sport relates to international students' psychological connection with the university. To date, no in-depth study has examined international students' college sport spectator experience and how the experience may influence students' 
university identity. In the current research, we explored the different social groups with which international students identify through college sport under the guidance of the Multiple Ingroup Identity Framework.

\section{The Multiple Social Identities of International Students}

Social identity is the part of one's self-concept derived from group membership, together with cognitive and emotional significance attached to that membership (Tajfel, 1974). Individuals build and maintain social identities by interacting and associating with various social groups with desirable memberships (Tajfel \& Turner 1979). Lock and Funk's (2016) Multiple Ingroup Identity Framework (MIIF) conceptualizes three levels of social groups with which individuals identify, labeled the superordinate group, sub-group, and relational group (see Figure 1). The outside circle in Figure 1 represents the superordinate group, which is the largest and most abstract social group. Identification with the superordinate group contributes to an individual's self-concept, self-esteem, and reduces subjective uncertainty (Brewer, 1991). In our research context, the superordinate group can be considered as the university, as it is the most abstract and inclusive group membership affiliated with a university.

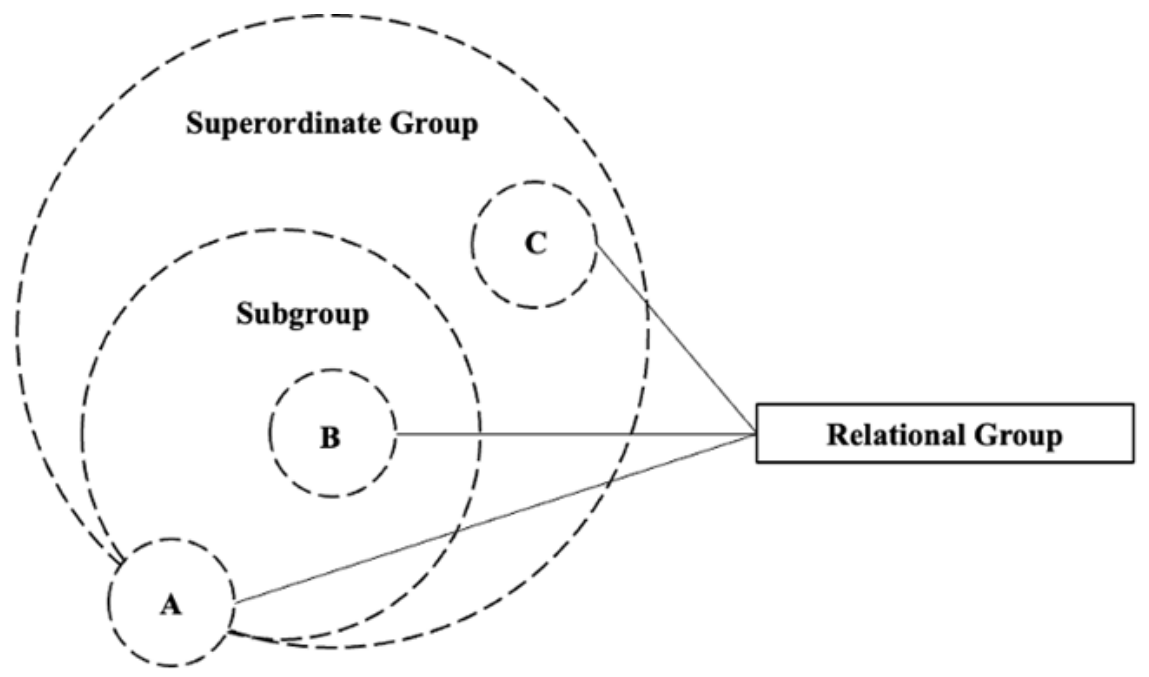

Figure 1. Superordinate Group, Subgroup, And Relational Group

Within the superordinate group, a sub-section of members may further identify with smaller and less inclusive subgroups. Subgroups are established based on group properties, such as group image and reputation (Zhang et al., 2014). A subgroup provides its members with a frame of reference that defines appropriate attitudes and behaviors, and members seek to incorporate these group properties into their self-concepts (Postmes et al., 2005). As a result, individuals are usually attracted to subgroups with desirable properties enhancing one's self-esteem (Dukerich et al., 2002; Hornsey, 2008). For college students, the subgroup may be a major, a class, a club, or the university's sport team. These subgroups provide students distinct memberships within the larger homogeneous university identity. 
Relational groups, represented by Circles A, B, and C in Figure 1, are the smallest and least inclusive social groups, where social interactions occur in smaller interpersonal networks. Relational groups arise from personalized bonds and social interdependence among members and may function within or aside from higher grouping levels (Brewer \& Gardner, 1996). Specifically, Circle A represents when relational group members are connected by relationships and associations that extend beyond superordinate and subgroup identities, such as when a person identifies with a sport team under external influence from friends and family (Funk \& James, 2006). Accordingly, the relational group can serve as a pre-existing external agent socializing an individual into a larger social group. In contrast, Circles B and C describe relational groups emerging from subgroup and superordinate memberships, respectively. For example, college students may form close social connections with each other through following the university's sport team (Wann et al., 2011) and joining sport fan communities (Yoshida et al., 2015). While the three types of relational groups (i.e., Circles A, B, and C) are formed through different mechanisms, they all stress emotional attachment, warmth, and interpersonal attractions among members, rather than group-level characteristics (Zhang et al., 2014). For our research context, the relational group may be a group of international students attending college sport games together as friends or students interacting with each other in a game and developing new relationships.

Past research has examined various social groups international students form through sport such as friends they meet through classes and sport activities (Li \& Zizzi, 2018), the university's sport teams (Kim et al., 2016), and students' heritage cultures as well as the American culture (Allen et al., 2010). The complex dynamic among these social identities, however, has not been adequately portrayed as these studies tend to examine one singular social group and overlooked intergroup relations. Students' identification with college sport relates to their university identity (Clopton, 2011) and this relationship has not been explored among international students. Lock and Funk (2016) advocated for more research on the various levels of social groups and their interconnections that might exist within a superordinate group. In the current research, we focus on subgroup and relational groups with which international students identify and to which they belong and how these groups contribute to international students' superordinate university identity. This leads to the first research question.

Research Question 1: How do international students' relational group and subgroup formed through college sport influence their university identification?

Addressing the first research question will provide new insight into the dynamics associated with international students' multiple identities. However, international students' college sport experience also involves cultural nuances. Many aspects of the college sport spectacle, such as tailgating, rituals, half-time entertainment, massive stadiums, and even the sport itself, can vastly differ from sports that exist in international students' countries of origin (McDonald \& Karg, 2014). Hence, college sport may present a cultural subject for international students. Given that seeking new cultural experiences is an important motivation for international students who study in the U.S. (Institute of International Education, n.d.), international students 
may use college sport as a tool to learn about and adjust to the culture of their university and the U.S. society. This cultural perspective is accounted for by the process of acculturation.

\section{Acculturation, College Sport, and Social Identity}

Acculturation happens when continuous first-hand contact between two different cultures results in changes in both cultural groups (Berry, 1997). In this process, one culture tends to maintain its heritage and determine the direction of cultural change, and the other culture adapts to the change (Berry et al., 1989). While past literature in acculturation has mostly focused on permanent migrants (e.g., Lee \& Funk, 2011), attention on short-term newcomers such as international tourists (e.g., Rasmi et al., 2014) and international students (e.g., Smith \& Khawaja, 2011) is growing.

Newcomers, such as international students, display a multitude of behavioral and cognitive changes when entering a new culture (Ramanathan, 2015; Ward, 2001). Behavioral changes include cultural-learning initiatives and the acquirement of culture-specific skills (Ward et al., 2009). Learning a new language and social skills are especially important for acculturating students from East Asia (Glass et al., 2014; Zhou et al., 2018). Cognitive changes due to acculturation influence cultural identity in terms of how newcomers recognize, categorize, and perceive themselves and others (Ward, 2001). While international students arrive in the U.S. with their heritage cultural identities, the cultural identities may change when students develop and adjust their knowledge and associations with the American culture (Berry et al., 1989). Identification with the heritage vs. host cultural group is at the root of intercultural-intergroup biases (Tajfel, 1974) and fundamental to the acculturation process (Ward, 2001).

Within sports management, scholarship on acculturation has largely mirrored broader sociological and psychological studies. Existing sport management research has underscored the positive relationship between sport participation (e.g., fitness classes, intramurals, sport clubs) and acculturation for the general college student population (e.g., Kim et al., 2016; Lee \& Funk, 2011) and international students (e.g., Allen et al., 2010; Glass et al., 2014). However, less is known about how acculturation operates in the sport spectator context and findings from prior research are inconsistent. Some studies report positive relationships between sport spectatorship and acculturation (Ha et al., 2014), whereas others report an insignificant relationship (Harrolle \& Trail, 2007; Li et al., 2015). For instance, in their study of Chinese immigrants in Australia, Li et al. (2015) found immigrants who watched Australian sports did not identify more as Australians than those who did not watch. Reflecting on the negative role played by leisure, including sport spectatorship, in the acculturation of Chinese international students, Zhou et al. (2018) called for more in-depth research on the complex interaction between sport and acculturation. Accordingly, our second research question draws on the behavioral and cognitive dichotomy of acculturation to examine how international students react and perceive college sport as a cultural subject.

Research Question 2: How do international students experience cultural learning and cultural identification at college sport games? 


\section{Method}

\section{Research Context}

Our research was conducted at a 4-year public university in a large city located in the northeastern U.S. At the time of the study, the university had approximately three thousand international students, constituting $7.3 \%$ of its total enrollment. The majority of international students were from East Asia, with approximately 50\% from China and $7 \%$ from South Korea. Data were collected when the university was focusing on expanding its international student enrollment but was experiencing difficulties engaging East Asian students, adding to the practical relevance of our study.

While the university hosted a variety of college sport programs, we focused on football given its dominant role in American culture, particularly at the intercollegiate level (Pratt, 2013). The university's football team competed in the NCAA's Division I (D-1) and had a heightened role in university life during our data collection due to the team's recent success. The university was seeking to leverage the increased prominence of its football team to engage international students by sending them game promotion emails, setting up special tailgate tents for them at home games, and offering them "Football 101" tutorial sessions to introduce football game rules. These outreach activities provided a salient context to gather in-depth information on the multiple social groups international students form through college football.

\section{Data Generation}

Data were collected through narrative interviews with international students who had attended at least one home university football game during the season in which seven home games were held. According to previous studies on other D-1 football programs, international students, on average, attend fewer than one game per season at their institutions (Kang at al., 2014; Kwon \& Trail, 2001). International students, especially East Asians, tend to have limited knowledge and experience with American football (Kang at al., 2014).

We collaborated with the university's Office of International Affairs to send out email invitations about the study. Students who were interested in the study contacted us to set up a time and location for the interview. We selected participants based on their gender, year in college, elapsed length of stay in the U.S., and nationality to ensure a variety of participants who were able to provide rich and diverse information on our research questions. Consummate with narrative interviewing, we focused on the depth of interviews as opposed to quantity to gather detailed and vivid accounts of participants (Anderson \& Kirkpatrick, 2016). After ten interviews, we noticed similar themes continued to emerge and extra interviews were not generating enough new information on the two research questions, indicating data saturation was achieved (Fusch \& Ness, 2015). Aligning with the research background, all ten participants were from East Asian countries (see Table 1). Pseudonyms were used to ensure confidentiality. 


\section{Table 1}

Participant Profiles

\begin{tabular}{lllll}
\hline Pseudonym & Gender & Country of Citizenship & Year in College & Tenure in U.S. \\
\hline JD & Male & China & Sophomore & 9 months \\
Mi & Female & Japan & Freshman & 4 months \\
Xi & Female & China & Junior & 4 months \\
Jo & Female & China & Graduate & 5 months \\
James & Male & China & Junior & 10 months \\
Jia & Male & China & Graduate & 2 years and 5 months \\
Soo & Female & South Korea & Graduate & 3 years and 4 months \\
Qi & Male & China & Graduate & 5 months \\
Cui & Female & China & Sophomore & 5 months \\
Yo & Male & South Korea & Junior & 5 months \\
\hline
\end{tabular}

The narrative interview technique we used stressed the construction and interpretation of meaning to produce a detailed and authentic portrait of participants' experiences (Riessman, 2008). Such practice is particularly useful when exploring research topics on identity as it can account for contextual, temporal, and structural fluidity in identity formation (Mishler, 2006). When research participants come from a marginalized group, as is the case with our participants - international students narrative interviews empower participants to help set the research agenda, such as deciding what information to disclose, so that an equal and healthy relationship is established between researchers and participants (Overcash, 2003). We, as researchers, served as active listeners, as opposed to pure interviewers, and focused on detailed and personal narratives provided by participants (Anderson \& Kirkpatrick, 2016).

While we encouraged interviewees to control the direction and pace of interviews, we prepared a list of semi-structured interview questions (e.g., open- and closed-ended questions, probing questions) to make sure our research questions were fully addressed. The interview questions tapped into four areas. First, we asked participants to describe their overall experience attending the university's football home games with questions such as "can you describe your most recent experience attending a [University] football game?" Second, there was a series of questions on relational group and subgroup, such as "who did you attend the game with?" and "did you interact with any other people during the game?" Third, the superordinate university identity was addressed with questions such as "how do you feel about [University] after attending football games?" Finally, the acculturation process was addressed with questions such as "did you talk to Americans during the game?" to target cultural learning behaviors, and "did attending football games change your perceptions of the U.S. or American people?" to elicit information on cultural identity.

Based on participants' answers, we used probing questions throughout the interviews to add depth and clarity to the answers given, which is particularly important when language barriers may be a concern (Welch \& Piekkari, 2006). We also took precautions to not interrupt participants to allow them to recount emotional or personally sensitive experiences (Riessman, 2008). All interviews were conducted face-to-face in English on the university campus and lasted approximately 40 to 60 minutes each. 


\section{Data Analysis}

Interview data were transcribed verbatim and imported into Dedoose (2018), a web application for facilitating qualitative data analysis. We followed an inductive coding approach to identify data-driven themes using the three-step procedure recommended by Corbin and Strauss (2008). The first step of analysis was open coding, in which we read interview transcripts sentence by sentence to identify information on students' social groups (i.e., relational group, subgroup, and superordinate group) and acculturation experience (i.e., cultural learning and cultural identification). Relevant sentences were assigned codes to reflect meaning of the data.

The second step was axial coding, in which two of the authors compared the codes, established relationships amongst them, and grouped codes with similar meanings into themes. For example, codes of "making new friends through football", "interaction with other people during games", and "football games are about socializing with friends" were grouped together under the theme "relational group is based on heritage cultural identity". This step yielded five themes. The final step was selective coding. We went through the quotes in each theme, identified representative quotes for the theme, and made connections amongst themes to address our two research questions.

To enhance the rigor of data generation and analysis, we adopted the credibility, transferability, dependability, and confirmability provisions for qualitative research recommended by Shenton (2004). For credibility, we adopted recognized techniques, including the use of narrative and semi-structured interviews, consistent with methods employed by previous research (e.g., Bhatia \& Ram, 2009). Moreover, thick descriptions were used to provide meaning and context to data (Tracy, 2010). For transferability, Shenton (2004) recommended providing background to the research context, which in our study involved providing a description of the university, its football program, the international student population, and university's attempts to use football to engage international students.

For dependability, we provided in-depth methodological descriptions of our data generation and analysis to make our study replicable (Flick, 2013). For confirmability, we focused on reducing researcher bias to the phenomenon under study. Authors of this research came from both Eastern and Western cultures, which encouraged us to account for our own beliefs, values, or reflexivity (Flick, 2013). We openly questioned each other's assumptions and the interpretation of data. This on-going process allowed us to reduce our biases and generate an accurate representation of findings (Shenton, 2004).

\section{Findings}

To address the first research question, the findings section begins with three themes on the relational group and subgroup formed around college football and their relationships to the superordinate university identity. To address the second research question, two themes regarding international students' behavioral and cognitive acculturation in college football games are presented. Text excerpts have been edited for clarity when appropriate. 


\section{Research Question 1}

Interviews revealed participants formed relationship groups based on their heritage culture. However, they also identified with a larger subgroup that included the entire football game spectator crowd. Involvement in the subgroup, which mainly consisted of American students, made participants feel integrated to the football spectacle and further led to the superordinate university identity. We organized these findings into three themes.

\section{Relational Group is Based on Heritage Cultural Identity}

Football games provided a time, space, and reason for international students to socialize with each other. JD highlighted the social function of football games, saying: "It [football game] is a term for party." In contrast, having no friend to attend games together resulted in a lack of continued attendance. Reflecting on the reasons she had only been to one football game, Soo explained: "If most of my friends are going to football games, I may want to join them. But since none of my friends really go [to the games], I did not go that often as well."

Direct social interactions in football games mostly occurred among international students themselves, and in many cases, among students from the same country (co-nationals). All participants indicated they received information about football events from somewhere "international," such as the university's international student office and informal online groups organized by international students such as a WeChat group for Chinese students. There was a lack of interaction with non-international entities. For instance, although Cui was confused about football game rules, she did not ask any American students sitting around her at games because: "They [American students] were chatting and talking about other things. I found it a little bit difficult [to ask them about the rules]." Xi attributed her lack of interaction with American students to language barriers, saying: "I think it would be hard for them to explain [the rules] to me. It is hard for us to communicate so I just gave up." Yo expressed concerns regarding his limited football knowledge, stating: "I go to football games with other international students. If we hang out with Americans, they may feel bored because we do not know much about football."

Even for the few participants who directly interacted with American students at football games, the interactions did not lead to a closer relationship. Jo, who claimed herself as an outgoing person and always looking to make friends, remarked:

I chatted with some American students in front of me a little bit. Everyone had a good time, but I did not make friends with them. We did not exchange [phone] numbers. That was good enough, I think. I do not know if I want to make friends with them.

\section{Identification with the Football Spectator Subgroup Is Facilitated by American Students}

In addition to forming relationships with their co-national peers, participants also connected with the larger football spectator crowd, which represented the subgroup. This spectator subgroup primarily comprised current students at the univer- 
sity, with American students as the majority and international students as the few. When describing the atmosphere at football games, participants consistently mentioned American students as a major observation of the football spectacle. For instance, Qi said:

They [American students] were crazy. The young people, you know. We sat in the student section, and when there was a touchdown, everyone stood up and cheered ... Yea, if people around start [to get] crazy and start to cheer, you just follow them, and then you feel different. ... I felt, at that moment, I was one of them [American students]. We all felt very happy from the bottom of our hearts. We [international students] cheered together with them [American students].

Sharing similar sentiment as Qi, many participants described the spectator crowd as "crazy" with a specific reference to American students. These "crazy" American students created an atmosphere that integrated international students into the spectator subgroup. James said: "During the game, you can see many American students wearing something crazy. That made me feel I am closer [to American students]." This quote showed despite limited direct interaction between international and American students, international students developed a stronger sense of belonging to the football spectator subgroup by observing American students and immersing themselves in the holistic game atmosphere.

Identification with the spectator subgroup was also developed when international students followed their American peers to practice the university's football rituals. Participants enjoyed learning university fight songs and chants and believed these rituals generated a sense of solidarity among game spectators. As JD described: "Everyone was cheering and wearing [the university colors], and there was the band, there was the cheerleading and fight songs. It is like all students are united together. I felt at that moment, I was one of them [the football spectator crowd].”

However, subgroup identification with the spectator crowd did not seem to extend beyond the stadium. Most participants did not identify themselves as fans of the university's football team and indicated the sense of belonging disappeared once they went back to their normal routine. Xi commented: "[During the game], I felt I was part of the crowd, and it felt like an honor to watch the game. But when I am back on campus, I feel I am just an ordinary student." It is worth noting that two participants, Qi and Jia, identified as football fans in general and had attended multiple football games. Qi played amateur flag football in China, and Jia developed his football fandom from his undergraduate program at another U.S. university. Yet, neither Qi nor Jia identified was a fan of the university's football team.

\section{Subgroup Identity Leads to University Identity}

Overall, participants believed they developed a stronger identification to the university through attending football games. They often mentioned how the pervasive university symbols at football games, such as university color, logo, and fight songs, instilled a sense of pride and belonging they would not experience otherwise. JD commented: "When you are in that atmosphere, you kind of love [University], and 
you dedicate yourself to [University]... It triggers your emotion to [sic] the university."

Many participants considered football games as a milestone in their life at the university. Some said it was not until attending football events that they started to develop some level of identification with the university. Jo told us about how her first football game attendance has changed her feelings toward the university:

I am a graduate student, and the university does not pay much attention to us. And I am an international student, so I do not really feel engaged in this culture. It was the night of the football game when I followed other students and cheered for football players. That was the first time I feel I am in [University], I am one of them [the university's students].

It appeared that enhanced university identity was primarily derived from international students' subgroup identification with the spectator crowd through American students, rather than the relational identification with their co-national peers. This was obvious when Cui, who had never talked to American students at football games, said: "It [going to football games] is good. I felt I was connected with American students, and we celebrated our school spirit together ... It is like every student is connected with each other." Cui's statement revealed football games gave international students an opportunity to connect with American students, who represented the majority group at the university. Football games were an avenue for international students to step out of their ordinary social circle to explore the social and cultural environment of the university, and thus develop university identity. Xi summarized this perspective:

I am new here and sometimes I do not really feel I belong [to the university]. That is why I want to go to football games and get to know more about [University] and then I can say "I am a [University] student!" ... It [attending football games] gave us a chance to go to an activity that all students belong to a group called [University]. It is really important for you to go out [of the daily on-campus routine] and meet those American people that you will not normally meet.

In contrast, failing to connect with the football spectator subgroup hindered university identification. Yo cheered for the opposing military university team in the game because: "When American students cheered for [University], I did not know what they were doing, so I could not feel that I am connected with them [the university's students] at all. I served the army in Korea for many years, so I cheered for the military team."

\section{Research Question 2}

Acculturation emerged as a significant component in participants' college football game experience. From the behavioral perspective, participants attended football games to practice English and develop a better understanding of the American culture. However, from the cognitive perspective, participants maintained their heritage cultural identity and perceived American students as the out-group. We used two 
themes to articulate the role of acculturation in international students' multiple-identity dynamic generated through college sport.

\section{Football Games as An Opportunity for Cultural Learning}

Participants experienced college football games as an avenue to acquire knowledge and skills specific to the American culture. Football was considered a symbol of America. This perception was salient when Yo explained his reason for attending football games: "I asked my friends to go [to football games] because it is a unique thing in America." Many participants shared this cultural learning motive as they described football as an "American thing" they had never experienced in their home countries.

Although there was limited interaction with American students directly, participants believed they gained a better understanding of the American culture merely by observing American students during football events. Telling us she was planning to attend more football games, Cui said:

I study in America, and I want to learn more about the tradition and culture here. I think football is one [aspect] of American culture. I want to see what American students do in their free time and what they do when they watch sports.

Some participants believed football games provided opportunities to practice English, with learning English as a part of learning the American culture. Despite never talking with American students during football games, Mi still believed attending football games was an effective way to practice English:

I want to say football is American culture. You know, staying at home is not improving English. If I go to the stadium, I have to use my English. I have two reasons to go to the stadium: to learn American culture and to learn English.

While most participants enjoyed attending the university's football games, few attended more than two games during the entire season. Many participants attributed their lack of consistent game attendance to educational obligations and other social activities, such as activities organized by the university's international student organizations. However, Qi, who was an avid football fan and had attended many football games at the university, had a different interpretation of the issue and commented: "They [other international students] may think that "American football is so popular so I should go take a look.' After that, they check it off their lists and never go again."

Qi's comments correctly reflected the real thoughts and experiences of many other participants. Although none admitted they went to football games to "check the list," many believed international students should go to football games to avoid regret. When asked how they would persuade other international students to attend a football game, many participants stated some variation of "at least go take a look so you will not regret it". Jia stated: "It [going to the football game] is like when you are in Beijing, you have to go to the Forbidden City. You just go there once so that you have no regret. If you don't like it, you do not need to go for the second time." 


\section{Intergroup Perceptions Based on Cultural Identity}

While participants were eager to learn about American culture, they hesitated to connect with the culture and its people on a deeper level. Participants showed heightened consciousness of differences between themselves and American students. When describing his feelings about football games, JD, a Chinese student, said: "My South Korean friend also told me he has never experienced this [football game] before. It was very different from our Asian culture."

Similar to JD, many participants used "they" to describe American students and "we" to describe international students who shared a similar cultural background. Such in- vs. out-group comparison attributed an outsider perspective to international students during football games. Despite taking part in tailgating and football rituals, participants tended to act as outsiders who observed and analyzed the spectacle rather than fully immerse in it. This outsider perspective manifested behaviors such as taking pictures of American students and posting pictures on social media. JD reflected on riding a university shuttle to the game:

We [a group of international students] took the shuttle together. During the trip, another shuttle passed by, and that shuttle was mostly filled with American students. They shouted very loudly to us and said: "Let's go, [University]!" I think it was very crazy. Most students on our shuttle were Asian, so we were very calm. We just looked at them [American students] and took pictures, and we posted the pictures on Facebook.

JD's story demonstrated a lack of social interaction between international and American students as the two groups took separate shuttle buses. More importantly, a sense of in- vs. out-group was obvious when JD interpreted American students' behavior as something extraordinary that was worth a camera capture. By labeling American students as "crazy" and Asian students as "calm," intergroup bias based on cultural identity emerged.

It also appeared that the longer participants had stayed in the U.S., the less they compared themselves with American students during football games. Neither Jia nor Soo, both of whom had stayed in the U.S. for more than two years, paid particular attention to American students. This was especially true for Jia, who had attended many football games as a football fan. Contrary to other participants, Jia used "they" to refer to international students:

I think internationally students are generally less engaged than domestic students. They [international students] are not as familiar with the sport as domestic students. If you did not grow up watching American football, it is very normal that you are less engaged than those who grew up watching it. Jia used a third person perspective to describe his understanding of international students in football games. Yet, this approach was an isolated case among participants. Jia was the only person with abundant football knowledge and a thorough U.S. life experience among the students who contacted us for interviews. 


\section{Discussion}

In this research, we explored the potential for institutions of higher education to use college sport to promote university identity among international students. We found support that college sport provides opportunities for international students to interact with domestic students but also creates barriers to bridging intergroup biases between the two student groups. Specifically, attending college sport games created meaningful interpersonal relationships and group-level associations for international students. However, college sport also sometimes highlighted differences between international and American students, thereby reinforcing intercultural intergroup biases. This finding supported the "double-edge sword" effect of sport in addressing integration issue in previous research (Clopton, 2011; Katz \& Heere, 2016; Zhou et al., 2018).

Figure 2 provides a visual presentation of the five identified themes. As the figure shows, the relational group has an external socialization role that functions aside from the superordinate group and subgroup (Lock \& Funk, 2016). Moreover, acculturation influences international students' identities through two different paths. The following section provides a discussion of our key findings to further interpret this figure.

\section{The Multiple-Identity Dynamic of International Students}

When international students attended college football games, they identified with both smaller relational groups that provided socialization opportunities and a broader sport spectator subgroup that provided a positive social image of being a football spectator and a student at the university. In Figure 2, the relational group operates in

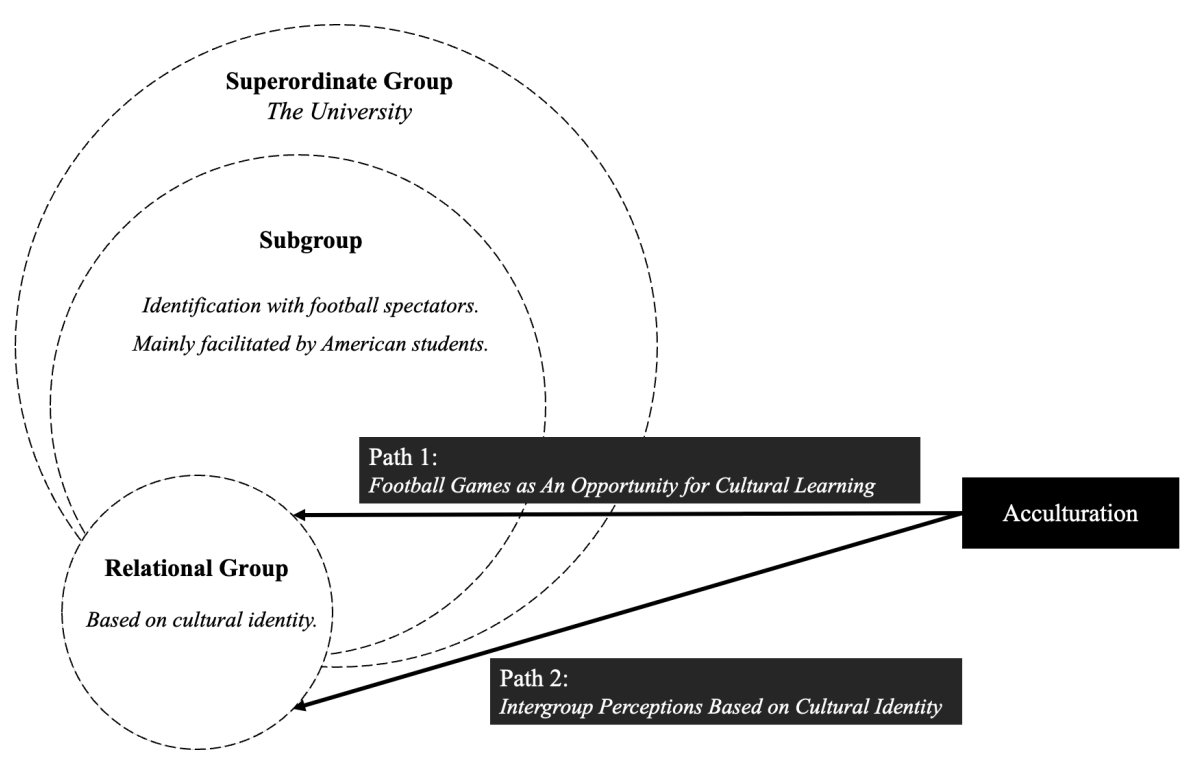

Figure 2. Multiple-ingroup Identities of International Students Through College Football 
conjunction, not within, the subgroup and superordinate group. This position aligns with Circle A in Figure 1, which suggests international students' relational groups did not emerge from the university or its sport programs, but from interpersonal relationships that extended beyond the university context (Lock \& Funk, 2016). Specifically, international students formed relational groups according to their heritage cultures that provided a sense of personal-level closeness and interdependence (Brewer \& Gardner, 1996). Within this exclusive and cohesive ecosystem, international students exchanged game-related information with each other and got involved in college sport as a group. As such, the relational group served as an external socialization agent that socialized international students into college sport and the university community (Funk \& James, 2001).

American students, who constituted the majority within the football spectator subgroup, were excluded from international students' relational group. The social divide between international and host-national students resulted from perceived social barriers between the two groups: international students felt inadequate in sport knowledge, language proficiency, and social skills to interact with host-nationals. When a minority group is perceived as inferior in sport ability to the majority group, sport participation can aggravate intragroup biases (Lee \& Scott, 2013). Our findings confirmed and extended this view in the context of sport spectatorship.

While international students avoided direct interpersonal interactions with American students, they connected to Americans on the subgroup level. The subgroup membership provided a sense of distinctiveness that enhanced international students' self-concept (Dukerich et al., 2002). As indicated by some participants, watching college football games together with American students elevated them from "ordinary" students to proud members of the university. International students expressed positive perceptions of American students and regarded American students as powerful agents who were able to accept them as a part of the sport spectator subgroup. Hence, although international students preferred to socialize with their co-national peers (i.e., the relational group), they sought to establish associations with American students in football games (i.e., the subgroup) given this subgroup has a relatively higher perceived status (Hornsey, 2008). This finding synthesized previous research on international students' multiple social identities (Allen et al., 2010; Kim et al., 2016; Li \& Zizzi, 2018) by discovering the multiple social groups international students identify with through college sport to meet different psychological needs.

\section{The Role of Acculturation in International Students' College Sport Experience}

Comparing the behavioral and cognitive aspects of acculturation helped us uncover two contradicting roles that acculturation played in international students' college sport game experience. The effects are illustrated by Path 1 and Path 2 in Figure 2. Pointing to the overlapping area between relational group and subgroup, Path 1 illustrates a positive influence in which acculturation contributes to international students' game attendance behavior. Participants used college football games to learn 
skills and knowledge of American culture. This cultural learning motive pushed international students to attend games, and therefore enhanced students' interactions with their international peers (i.e., relational group) and identification with other game spectators (i.e., subgroup). This effect corresponds with the behavioral approach to acculturation focused on cultural learning (Wards, 2001).

In contrast, Path 2 shows a negative influence by pointing to the part of relational group that excludes the subgroup. Extending previous research on the cultural significance of college sport (McDonald \& Karg, 2014), we found international students associated college football with intensive cultural meaning that heightened their cultural awareness. This awareness led to constant comparisons of how international students act and think differently from American students and inhibited the development of a strong shared identity between the two student groups (Tajfel \& Turner 1979). Participants often referred to American students as "they" and international students as "we", indicating group membership based on culture identity. Moreover, cultural labels such as "Americans are crazy" vs. "Asians are calm" indicated intercultural bias as a result of intergroup comparisons (Tajfel \& Turner 1979).

The opposing effects of Path 1 and Path 2 revealed a complex interaction between college sport and acculturation among international students. Previous research has provided evidence on both positive and negative social impacts of college sport in the university community (e.g., Clopton, 2011). The acculturation literature has discerned behavioral and cognitive changes in newcomers in response to a new culture (e.g., Ramanathan, 2015). By connecting college sport with acculturation, we found while international students were interested in American football and the culture surrounding it, they hesitated to establish connections with the American culture and American students on a more personal and meaningful level. Hence, although acculturation motivated international students' college sport spectating behavior, which provided opportunities for university identification, it also highlighted intergroup cultural biases that hindered university identification. This finding draws attention to the potentially negative role of college sport in addressing the integration of international students (Zhou et al., 2018).

\section{Practical Implications}

The current research offered practical insights into how college sport could be optimized to integrate international students into university communities. A major finding of this research was that international students formed exclusive relational groups based on cultural identity. Universities should use more effective communication strategies to bridge gaps with smaller exclusive groups. For example, universities and athletic departments can disseminate game information through channels familiar to international students, such as WeChat and KakaoTalk, two social media platforms popular among Chinese and Korean nationals, respectively.

Given American students served as the primary agents for international students' subgroup identification, universities should design activities that foster quality interactions between international and American students in college sport events. Existing programs implemented by universities, such as the Football 101 session, 
have mainly focused on improving international students' sports knowledge. However, our findings indicated language and social skills are also crucial concerns when international students attend sport events. Universities should consider socially and linguistically oriented programs for international students to practice language in non-academic social environments. For example, universities could implement a program in which international students are paired with American students and watch college sporting events to facilitate cultural learning.

More efforts should be directed at bridging intergroup biases between international and American students. Existing practices such as setting up special tailgating zones for international students might have the unintended consequence of highlighting intergroup differences and reinforcing stereotypes. Instead, college sport events should promote socialization that highlights intergroup similarities to foster shared university identity among students of different backgrounds. Using sports familiar to international students, such as college basketball and soccer, may be more effective in bridging the intergroup gap.

Importantly, universities should be aware that international students desire a sense of belonging to the university. While universities are now placing greater emphasis on diversity, equity, and inclusion, a major finding of this research was the limitation of college sport in addressing international students' integration issue as international students perceive many obstacles when interacting with American students in college sport. International students still feel inferior to their American peers and lack confidence and sense of power within the university community. East Asian students are especially vulnerable to such perceptions as they tend to be stereotyped as unsociable and physically unattractive (Lin et al., 2005). The intense social and cultural elements of college sport may alienate international students if they are not designed in ways that embrace and empower international students as essential in-group members. Universities could utilize expertise from various academic and auxiliary departments (e.g., sport management, student affairs, athletes, campus recreation) to promote global sport education that enables international and domestic students to exchange knowledge and find commonalities as sport spectators. Such a program would reduce intergroup biases and promote two-way communication to allow international students a more proactive role in the learning process. Overall, universities can utilize college sport to facilitate a shared sense of identity and belonging to shape university culture, rather than requiring international students to conform to existing norms in order to gain in-group status.

\section{Limitations and Future Research}

We recognize limitations of our research related to the research context, sampling, and the general methodology used. First, the research was conducted in the context of an NCAA D-I football program. A different study context, such as a different university with a different sport program, could produce different findings. For example, interactions between international and American students in the context of college basketball or soccer might differ from football due to students' different knowledge and previous experience with these sports. However, we believe using 
college football as the research context provided valuable insights to address our research questions because of its crucial role at U.S. college campuses (Pratt, 2013). Future studies can compare international students' experience with different college sports to examine how familiarity with the sport influences students' identification.

We focused on international students from East Asian countries given their significant contribution to U.S. universities. Findings might be different if we recruited international students from Australia, Canada, New Zealand, and United Kingdom given cultural and language similarities between the U.S. and these countries (Harrison \& Peacock, 2009). Future studies can address this limitation and compare international students from different cultures and countries to further understand the role of college sport in fostering the university identity of international students.

In order to collect rich information on our research questions, we recruited participants who had attended at least one football game at the university. Hence, the findings may only be applicable to international students who are interested in college football and open to sharing their experience with us. Students who were disinterested in college sport or unwilling to integrate into the university culture might have been excluded from the study. Future research should reach out to this group of students to understand factors that negatively impact their game attendance and inform strategies for attracting more international students to college sport games.

Interestingly, we observed that students' existing football fandom and life experience in the U.S. influenced their perceptions of and reactions to college football. For example, participant Jia, who had stayed in the U.S. for more than two years and had strong knowledge and interest in football, appeared to be less sensitive to the cultural elements of college football compared with other participants. Future research can examine how sport knowledge and understanding of American culture interact to influence international students' university identification.

Finally, while our qualitative methodology enabled in-depth understanding to address our research questions, we recognize its limitations in generalizing findings (Gratton \& Jones, 2014). Our research uncovered interesting relationships that await future inquiry on a larger scale. Future research can collect quantitative data from international students to test the relationships among relational, subgroup, and superordinate identities to further understand their interactions with acculturation.

\section{References}

Allen, J. T., Drane, D. D., Byon, K. K., \& Mohn, R. S. (2010). Sport as a vehicle for socialization and maintenance of cultural identity: International students attending American universities. Sport Management Review, 13(4), 421-434.

Anderson, C., \& Kirkpatrick, S. (2016). Narrative interviewing. International Journal of Clinical Pharmacy, 38(3), 631-634.

Bhatia, S., \& Ram, A. (2009). Theorizing identity in transnational and diaspora cultures: A critical approach to acculturation. International Journal of Intercultural Relations, 33(2), 140-149. 
Berry, J. W. (1997). Immigration, acculturation, and adaptation. Applied Psychology, 46(1), 5-34.

Berry, J. W., Kim, U., Power, S., Young, M., \& Bujaki, M. (1989). Acculturation attitudes in plural societies. Applied Psychology, 38(2), 185-206.

Brewer, M. B. (1991). The social self: On being the same and different at the same time. Personality And Social Psychology Bulletin, 17(5), 475-482.

Brewer, M. B., \& Gardner, W. (1996). Who is this "We"? Levels of collective identity and self representations. Journal of Personality and Social Psychology, 71(1), 83-93.

Brunette, C., Vo, N., \& Watanabe, N. M. (2017). Donation intention in current students: an analysis of university engagement and sense of place in future athletic, academic, and split donors. Journal of Issues in Intercollegiate Athletics, 10, 78-100.

Cho, J., \& Yu, H. (2015). Roles of university support for international students in the United States: Analysis of a systematic model of university identification, university support, and psychological well-being. Journal of Studies in International Education, 19(1), 11-27.

Clopton, A. W. (2011). Social capital and college sport: In search of the bridging potential of intercollegiate athletics. Journal of Intercollegiate Sport, 4(2), 174189.

Corbin, J., \& Strauss, A. (2008). Basics of qualitative research: Techniques and procedures for developing grounded theory (3rd ed.). Sage.

Dedoose. (2018). Dedoose (Version 8.0.42) [Web application]. Retrieved from https://dedoose.com

Dukerich, J. M., Golden, B. R., \& Shortell, S. M. (2002). Beauty is in the eye of the beholder: The impact of organizational identification, identity, and image on the cooperative behaviors of physicians. Administrative Science Quarterly, 47(3), 507-533.

Flick, U. (2013). The SAGE handbook of qualitative data analysis. Sage.

Forbes-Mewett, H., \& Pape, M. (2019). Social capital and the US college experiences of international student-athletes and non-athletes. Journal of International Students, 9(3), 777-794.

Frey, L. L., \& Roysircar, G. (2006). South Asian and East Asian international students' perceived prejudice, acculturation, and frequency of help resource utilization. Journal of Multicultural Counseling and Development, 34(4), 208-222.

Funk, D. C., \& James, J. (2001). The psychological continuum model: A conceptual framework for understanding an individual's psychological connection to sport. Sport Management Review, 4(2), 119-150.

Funk, D. C., \& James, J. (2006). Consumer loyalty: The meaning of attachment in the development of sport team allegiance. Journal of Sport Management, 20(2), 189-217.

Fusch, P. I., \& Ness, L. R. (2015). Are we there yet? Data saturation in qualitative research. The Qualitative Report, 20(9), 1408-1416. 
Glass, C. R., Gómez, E., \& Urzua, A. (2014). Recreation, intercultural friendship, and international students' adaptation to college by region of origin. International Journal of Intercultural Relations, 42, 104-117.

Gratton, C., \& Jones, I. (2014). Research methods for sports studies. Routledge.

Ha, J. P., Hums, M. A., \& Greenwell, C. T. (2014). The impact of acculturation and ethnic identity on American football identification and consumption among Asians in the United States. International Journal of Sports Marketing \& Sponsorship, 15(2). 125-142.

Harrolle, M. G., \& Trail, G. T. (2007). Ethnic identification, acculturation and sports identification of Latinos in the United States. International Journal of Sports Marketing \& Sponsorship, 8(3), 29-48.

Harrison, N., \& Peacock, N. (2009). Cultural distance, mindfulness and passive xenophobia: Using integrated threat theory to explore home higher education students' perspectives on 'internationalisation at home'. British Educational Research Journal, 36(6), 877-902.

Holtbrügge, D., \& Engelhard, F. (2016). Study abroad programs: Individual motivations, cultural intelligence, and the mediating role of cultural boundary spanning. Academy of Management Learning \& Education, 15(3), 435-455.

Hornsey, M. J. (2008). Social identity theory and self-categorization theory: A historical review. Social and Personality Psychology Compass, 2(1), 204-222.

Inoue, Y and Berg, BK and Chelladurai, P (2015) Spectator sport and population health: A scoping study. Journal of Sport Management, 29(6). 705-725.

Institute of International Education. (n.d.). International Students in the United States. Institute of International Education. Retrieved from https:/www.iie. org/-/media/Files/Corporate/Publications/International-Students-in-the-US. ashx?la=en\&hash=CBD3CF0CF874EB50962C774D73011EC24BD6F6DC

Jones, R., \& Kim, Y. S. (2013). Communication experiences of international students in the US: A comparison study of cross-cultural adaptation between European and Asian students. Scientia et Humanitas, 3, 83-104.

Kang, C., Lee, J., \& Bennett, G. (2014). Comparative analysis of sport consumer motivation affecting sport consumption behavior between American and Asian international students. International Journal of Sport Management, 15, 286-310.

Katz, M., \& Heere, B. (2016). New team, new fans: A longitudinal examination of team identification as a driver of university identification. Journal of Sport Management, 30(2), 135-148.

Kim, J. C., Gau, L. S., \& Kim, K. T. (2016). Examination on the relationships among school identification, team identification, and sport consumption behavior of university students. International Journal of Research in Social Sciences, 6(3), 704-723.

Kwon, H., \& Trail, G. (2001). Sport fan motivation: A comparison of American students and international students. Sport Marketing Quarterly, 10(3), 147-155.

Lapchick, R. (2010). The effect of the economic downturn on college athletes and athletic departments on issues of diversity and inclusion. Journal of Intercollegiate Sport, 3(1), 81-95. 
Lee, Y. S., \& Funk, D. C. (2011). Recreational sport participation and migrants' acculturation. Managing Leisure, 16(1), 1-16.

Lee, J., \& Opio, T. (2011). Coming to America: Challenges and difficulties faced by African student athletes. Sport, Education and Society, 16(5), 629-644.

Lee, K. J., \& Scott, D. (2013). Interracial contact experience during recreational basketball and soccer: Korean American males' perspectives. Journal of Leisure Research, 45(3), 267-294.

Li, K. C., Sotiriadou, P., \& Auld, C. (2015). An examination of the role of sport and leisure on the acculturation of Chinese immigrants. World Leisure Journal, 57(3), 209-220.

Li, J., Wang, Y., \& Xiao, F. (2019). East Asian international students and psychological well-being: A systematic review. Journal of International Students, 4(4), 301-313.

Li, S., \& Zizzi, S. (2018). A case study of international students' social adjustment, friendship development, and physical activity. Journal of International Students, 8(1), 389-408.

Lin, M. H., Kwan, V. S., Cheung, A., \& Fiske, S. T. (2005). Stereotype content model explains prejudice for an envied outgroup: Scale of anti-Asian American stereotypes. Personality and Social Psychology Bulletin, 31(1), 34-47.

Lock, D. J., \& Funk, D. C. (2016). The multiple in-group identity framework. Sport Management Review, 19(2), 85-96.

McDonald, H., \& Karg, A. J. (2014). Managing co-creation in professional sports: The antecedents and consequences of ritualized spectator behavior. Sport Management Review, 17(3), 292-309.

Mishler, E. (2006). Narrative and identity: The double arrow of time. In A. De Fina, D. Schiffrin, \& M. Bamberg (Eds.), Discourse and Identity (Studies in Interactional Sociolinguistics, pp. 30-47). Cambridge University Press.

Moody, J. (2020). U.S. World News. Study: International student numbers in U.S. drop. Retrieved from https://www.usnews.com/education/best-colleges/articles/ annual-study-international-student-numbers-in-us-drop

National Foundation for American Policy. (2018). Immigrants and billion-dollar companies. Retrieved from https://nfap.com/wp-content/uploads/2019/01/2018-BILLION-DOLLAR-STARTUPS.NFAP-Policy-Brief.2018-1.pdf

NAFSA (2020). NAFSA: Association of International Educators. New NAFSA data show first ever drop in international student economic value to the U.S. Retrieved from https://www.nafsa.org/about/about-nafsa/new-nafsa-data-show-first-ever-drop-international-student-economic-value-us

Overcash, J. A. (2003). Narrative research: A review of methodology and relevance to clinical practice. Critical Reviews in Oncology/Hematology, 48(2), 179-184.

Popp, N., Hums, M. A., \& Greenwell, T. C. (2009). Do international student-athletes view the purpose of sport differently than United States student-athletes at NCAA division I universities?. Journal of Issues in Intercollegiate Athletics. 2, 93-110. 
Postmes, T., Spears, R., Lee, A. T., \& Novak, R. J. (2005). Individuality and social influence in groups: Inductive and deductive routes to group identity. Journal of Personality and Social Psychology, 89(5), 747-763.

Pratt, A. N. (2013). Integrated impression management in athletics: A qualitative study of how NCAA Division I athletics directors understand public relations. International Journal of Sport Communication, 6(1), 42-65.

Quinton, W. J. (2020). So close and yet so far? Predictors of international students' socialization with host nationals. International Journal of Intercultural Relations, 74, 7-16.

Ramanathan, V. (2015). Values, behaviour and identity: Acculturation of Indian immigrant men in Australia. Journal of International Migration and Integration, 16(3), 625-638.

Rasmi, S., Ng, S., Lee, J. A., \& Soutar, G. N. (2014). Tourists' strategies: An acculturation approach. Tourism Management, 40, 311-320.

Riessman, C. K. (2008). Narrative methods for the human sciences. Sage.

Shenton, A. K. (2004). Strategies for ensuring trustworthiness in qualitative research projects. Education for Information, 22(2), 63-75.

Smith, R. A., \& Khawaja, N. G. (2011). A review of the acculturation experiences of international students. International Journal of Intercultural Relations, 35(6), 699-713.

Steiner, L., Sundström, A. C., \& Sammalisto, K. (2013). An analytical model for university identity and reputation strategy work. Higher Education, 65(4), 401-415.

Tajfel, H. (1974). Social identity and intergroup behaviour. Information (International Social Science Council), 13(2), 65-93.

Tajfel, H., \& Turner, J. (1979). An integrative theory of intergroup conflict. In W. Austin \& S. Worchel (Eds.), The social psychology of intergroup relations (pp. 33-47). Brooks/Cole Publishing Company.

Toma, J. D. (2003). Football U.: Spectator sports in the life of the American university. University of Michigan Press.

Tracy, S. J. (2010). Qualitative quality: Eight "big-tent" criteria for excellent qualitative research. Qualitative Inquiry, 16(10), 837-851.

Wann, D. L., Brame, E., Clarkson, M., Brooks, D., \& Waddill, P. J. (2008). College student attendance at sporting events and the relationship between sport team identification and social psychological health. Journal of Intercollegiate Sport, 1(2), 242-254.

Wann, D. L., Waddill, P. J., Polk, J., \& Weaver, S. (2011). The team identificationsocial psychological health model: Sport fans gaining connections to others via sport team identification. Group Dynamics: Theory, Research, and Practice, 15(1), 75-89.

Ward, C. (2001). The A, B, Cs of acculturation. In D. Matsumoto (Ed.), The handbook of culture and psychology (p. 411-445). Oxford University Press.

Ward, C., Masgoret, A. M., \& Gezentsvey, M. (2009). Investigating attitudes toward international students: Program and policy implications for social integration and international education. Social Issues and Policy Review, 3(1), 79-102. 
Welch, C., \& Piekkari, R. (2006). Crossing language boundaries: Qualitative interviewing in international business. Management International Review, 46(4), 417-437.

Wu, H. P., Garza, E., \& Guzman, N. (2015). International student's challenge and adjustment to college. Education Research International, 2015, 1-9.

Yoshida, M., Gordon, B. S., Heere, B., \& James, J. D. (2015). Fan community identification: An empirical examination of its outcomes in Japanese professional sport. Social Marketing Quarterly. 24(2). 105-119.

Zhang, S., Chen, G., Chen, X. P., Liu, D., \& Johnson, M. D. (2014). Relational versus collective identification within workgroups: Conceptualization, measurement development, and nomological network building. Journal of Management, 40(6), 1700-1731.

Zhou, Y., Zhang, H., \& Stodolska, M. (2018). Acculturative stress and leisure among Chinese international graduate students. Leisure Sciences, 40(6), 557-577. 